\title{
You Need to Know More to Understand My Scoring on the Survey: Free-Text Comments as Part of a PROM-Survey of Men with Prostate Cancer
}

\author{
Senada Hajdarevic ${ }^{1}$, Birgit H. Rasmussen ${ }^{2}$, Per Fransson ${ }^{1}$ \\ ${ }^{1}$ Department of Nursing, Umeå University, Umeå, Sweden \\ ${ }^{2}$ Department of Health Sciences, Lund University, Lund, Sweden \\ Email: senada.hajdarevic@umu.se
}

Received 4 April 2016; accepted 7 May 2016; published 10 May 2016

Copyright (C) 2016 by authors and Scientific Research Publishing Inc.

This work is licensed under the Creative Commons Attribution International License (CC BY). http://creativecommons.org/licenses/by/4.0/

(c) (i) Open Access

\section{Abstract}

Prostate cancer and its treatment have long-term implications for men's lives. We aimed to describe the content, extent, and frequency of written comments to the open-ended question, "Further comments?" in the patient-reported outcome measures questionnaire. During the study period, 897 men participated; 372 wrote 747 free-text comments in the questionnaire. These comments were analysed using qualitative content analysis and were grouped into four categories: 1) prostate cancer's influence on health; 2) clarifications of answers to the survey; 3) descriptions of well-being despite the cancer; and 4) experiences of care and the need for contact with health care. The distribution of the comments shifted over time. The open-ended question not only allowed the participants to explain their other responses and describe important aspects of their lives during and after treatment, something not normally covered by a questionnaire, but it also indicated their experiences of health care services along the patients' PC-trajectory. This further raises the issue of including an open-ended item in a forced-choice survey into the ethical realm to ensure that proper care is taken of participants' answers and thoughts.

\section{Keywords}

Prostate Cancer, Questionnaire, Open-Ended Question, Information, Feedback, Quality of Life, Nursing 


\section{Introduction}

Prostate Cancer (PC) is the most common type of cancer among men in Sweden, with 9678 new cases in 2013 [1]. The disease often develops slowly and is confined to the prostate gland. When the tumour is large enough to pinch the urethra it can cause urinary problems and/or affect sexual function. Other symptoms of PC can include skeletal pain and fatigue [2]. One of a number of treatments for PC is External Beam Radiotherapy (EBRT), which allows high local control relative to the delivered dose.

The daily lives of men with PC are strongly influenced by learning of the diagnosis, living with the symptoms, undergoing treatments, and experiencing side-effects [3]-[5]. The side-effects of EBRT include gastrointestinal, genitourinary, or erectile dysfunction [3] [6] [7]. Pain, fatigue, and existential concerns add to the distress these patients live with [2], and the effects of PC can also influence the Health-Related Quality of Life (HRQOL) of the patients' partners and their whole family [8] [9]. Surveys have used Patient-Reported Outcome Measurement (PROM) questionnaires to assess HRQOL among men who have been treated for PC [3] [6] [8]. However, it is not certain whether the closed-ended questions in such questionnaires sufficiently capture the patients' experiences of HRQOL or if there are other important HRQOL-related dimensions which such questions do not address.

There is an ongoing discussion about the advantages and disadvantages of including open-ended items in a questionnaire. Some questionnaires have included open-ended questions to elicit feedback and to gain insight into how to analyse the other answers [10] [11], but also to get more information about patients' experiences of cancer care and how this care could be improved towards a more person-centred approach [12] [13].

There are, however, a number of problems with the use of open-ended questions. They are expensive to produce and to score; they are not standardized; and it is difficult to estimate how many participants (10\% to $70 \%$ in published studies [12]-[16]) will take the opportunity to provide comments on such questions. Open-ended questions also have technical constraints in relation to handwriting, grammar, long words, and the amount of space available to write in. Respondents' level of education, interest in the survey, and ability to articulate may also affect their written comments [11] [17]. Analysis of such data also requires considerable resources and may provide important information about supplementary explanations to the answers in the questionnaires.

Our ongoing HRQOL studies conducted over the past 15 years have involved the collection of a large sample of PROM including HRQOL data [8] [18] [19]. In our PROM-questionnaire, men diagnosed with prostate cancer had the opportunity to write anything they felt important to describe or clarify in the general open-ended question. The open-ended question has never previously been explored in this population. The aim of this study was therefore to report the extent of use of open-ended questions and to describe what patients express when responding to such questions in a PROM-questionnaire.

\section{Methods}

\subsection{Participants}

The cohort comprised men from the ongoing long-term HRQOL follow-up in the Northern Region of Sweden [20]. From 1 January 1992 to 1 June 2002, all men in the region with localized PC referred to EBRT for treatment were offered the opportunity to participate in the prospective HRQOL evaluation. These men were given five fractions per week of 3-D conformal EBRT, with a daily dose of 2.0 Gy (mean total dose 74.0 Gy). A PROM-questionnaire containing an open-ended question was included in their QOL evaluation. The study consecutively recruited 897 men who completed a total of 4443 questionnaires during the study period. Of these 897 patients, 372 (41\%) wrote between one to eight comments in the questionnaires during this period (Table 1). The characteristics of the participants at baseline are presented in Table 2. These 372 patients with 2520 completed questionnaires resulted in a total of 756 written comments among a total of 749 questionnaires (17\%) with comments.

\subsection{Data Collection}

All men were asked by a nurse at the radiotherapy department to participate in the HRQOL study on their first day of EBRT. They were asked to complete the paper-based questionnaire on the first (baseline) and last day of treatment (end of radiotherapy) and to return the completed questionnaires to the staff. All recruited patients were then mailed a paper-based questionnaire at nine specific follow-up times: 3 months, and 1, 2, 3, 5, 8, 10, 12, 
Table 1. Numbers of comments per participants.

\begin{tabular}{|c|c|}
\hline Number of comments (756 in total") & Numbers of participants $(n=372)$ \\
\hline 1 comment & 168 \\
\hline 2 comments & 105 \\
\hline 3 comments & 52 \\
\hline 4 comments & 28 \\
\hline 5 comments & 9 \\
\hline 6 comments & 6 \\
\hline 7 comments & 3 \\
\hline 8 comments & 1 \\
\hline
\end{tabular}

*Of these 756 comments, 9 were excluded from the analysis.

Table 2. Characteristics of the participants at baseline.

\begin{tabular}{lc}
\hline & Participants (n = 372) \\
\hline Age (years) & \\
Mean & 64.7 \\
Range & $44-78$ \\
Living with partner, n (\%) & \\
Yes & $310(83)$ \\
No & $22(6)$ \\
Missing & $40(11)$ \\
Educational level, n (\%) & \\
Elementary school & $103(28)$ \\
Secondary school & $9(2)$ \\
Training school & $36(10)$ \\
University level & $43(11)$ \\
Other & $65(18)$ \\
Missing & $116(31)$ \\
Employment level, n (\%) & \\
Working & $117(32)$ \\
Retired & \\
Disability retired & $10(2)$ \\
Other & \\
Missing & $(61)$ \\
& \\
\hline
\end{tabular}

and up to 15 years after final treatment. One reminder was sent to those who did not respond within 4 weeks. Informed consent was obtained from all participants prior to taking part.

\subsection{Instrument}

The questionnaire, Prostate Cancer Symptom Scale (PCSS; former named QUFW94) is a validated self-assess- 
ment questionnaire designed to evaluate PROM after treatment of localized PC [21]. The questionnaire contained four main categories: 1) general (i.e., life situation, limitations in daily life); 2) urinary symptoms; 3) bowel symptoms; and 4) sexual function. The questions are responded to on a modified linear-analogue scale containing values between 0 and 10, where $0=$ "no problem/very good function" and $10=$ "many problems/very bad function". The patients were asked to evaluate their symptoms during the previous week, and at the end of the questionnaire they were given an opportunity in the open-ended question to write "overall comments."

\subsection{Analysis}

The comments were transcribed verbatim and analysed with qualitative content analysis [22]. We first read all comments to obtain a sense of the whole. Nine of these comments were $(9 / 756 ; \sim 1 \%)$ unreadable and excluded from the analysis. The analysis thus includes a total of 747 written comments. The comments were then sorted into meaning units, which could range from one word to a line or longer of significant content or meaning [22] [23]. The meaning units were condensed, and each was labelled with a code capturing its core. Codes with similar meanings were then sorted into subcategories and finally into categories [23]. The analysis was not a linear process of interpretation, but rather a process of moving forward and back between the whole and the part and the manifest content in the text [23] [24]. During the analysis, the codes and categories were discussed between authors until a consensus was reached. The categories, which were based on the participants' comments, were organized to present the panorama of patients' experiences of the disease, their health-care, and their life, and are presented in Table 3.

\subsection{Statistical Analysis}

All statistical calculations were conducted with the IBM SPSS statistics program, version 22 (IBM, Armonk, NY, USA). Descriptive data of participants' characteristics were analysed and reported as numbers, mean values, and proportions. The men's ages were summarized using mean and range and comparison with non-participants was performed by the Mann-Whitney Test. Comparison with non-participants regarding living status (partner) was performed by using Chi-2-test. Since a large proportion (>75\%) of missing data in the non-participant group related to education levels and employment, comparison of these variables between the two groups was inapplicable.

\subsection{Ethics}

Permission to perform the study was given by the Ethics Committee of the Faculty of Medicine at the Umeå University, Sweden and followed the ethical principles in accordance with the Helsinki declaration for medical research (WMA).

\section{Results}

During the study period 372 (41\%) of the participants had responded at least once to the open-ended question, corresponding to $17 \%$ of the 4443 returned questionnaires. Nearly half $(n=168)$ of the participants wrote one

Table 3. Categories and codes identified from the comments.

\begin{tabular}{|c|c|}
\hline Category & Codes \\
\hline Prostate cancer's influence on health & $\begin{array}{l}\text { Description of the progress of PC } \\
\text { Treatment of PC } \\
\text { The problems of living with PC } \\
\text { Other health topics }\end{array}$ \\
\hline Clarifications of answers to the survey & $\begin{array}{l}\text { Additional information } \\
\text { Explanations of other answers }\end{array}$ \\
\hline Descriptions of well-being despite the cancer & $\begin{array}{l}\text { Acceptance of the disease } \\
\text { Living normal everyday life in the present } \\
\text { Feeling able to do things }\end{array}$ \\
\hline Experiences of care and need for contact with the health care & $\begin{array}{l}\text { Need for information and response from health-care } \\
\text { Expressing greetings to staff and gratitude for care } \\
\text { Expressing dissatisfaction and negative experiences of health-care }\end{array}$ \\
\hline
\end{tabular}


comment, and the rest two to seven comments during their years of participation in the study (Table 1). Compared to non-participants at baseline, the participants were younger (64.7 \pm 6.1 vs. $65.8 \pm 6.1, \mathrm{p}=0.006$ ) and more often lived with partners $(83 \%(n=310)$ vs. $78 \%(n=412), p=0.011$; data not shown). The 747 handwritten comments were between one and 101 words long. Our overall impression from the men's handwritten comments was that they perceived the open-ended question as an opportunity to relate more about their health and health-care than had been asked for in the closed questions. Each meaning unit of the men's comments was sorted into one of the following four categories: 1) prostate cancer's influence on health; 2) clarifications of answers to the survey; 3) descriptions of well-being despite the cancer; and 4) experiences of care and a need for contact with the health care. The categories and codes described below are displayed in Table 3 . The distribution of comments is shown in Figure 1, and the change in the distribution of comments over time is presented in Figure 2. The content of patients' free-text comments illustrate a variation of experiences and needs related to their health, life and treatment, and how these experiences and needs are changing over time.

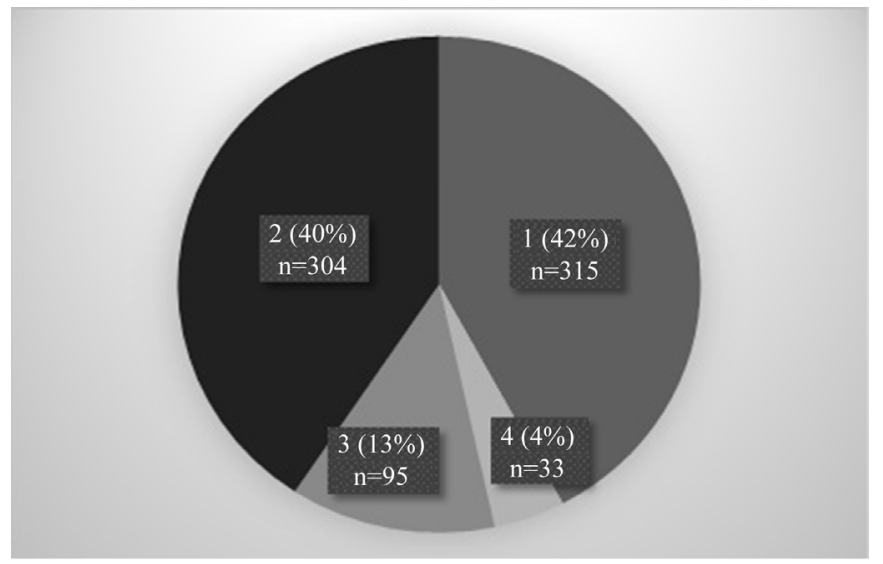

Figure 1. Proportions of the 747 comments within the four categories: 1) prostate cancer's influence on health, 2) clarifications of answers to the survey, 3) descriptions of well-being despite the cancer, and 4) experiences of care and need for contact with the health care.

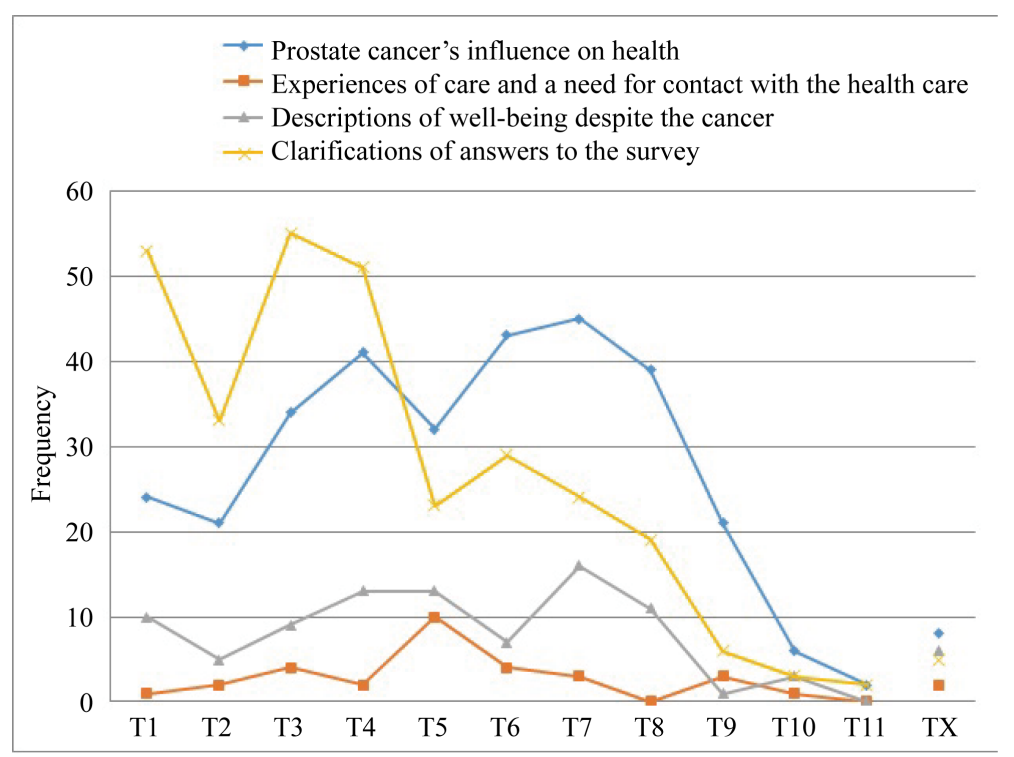

Figure 2. Distribution of the 756 comments stratified into categories over the follow-up times. T1: baseline; T2: end of radiotherapy; T3: 3 months; T4: 1 year; T5: 2 years; T6: 3 years; T7: 5 years; T8: 8 years; T9: 10 years; T10: 12 years; T11: 15 years; TX: extra occasion. 


\subsection{Prostate Cancer's Influence on Health}

Of the men's comments, 42\% (315/747) were sorted into this category, which contains two subcategories of patients' perspectives about PC. The first subcategory comprises the disease-related current situation including facts about the progress, treatment, and drugs currently used to manage the PC. The second subcategory focuses on patients' experiences of PC-related symptoms, including the problems of living with PC and other diseases that undermine health and add to experiences of illness.

Comments in the first subcategory were expressed using medical terminology, describing the current state of the disease and whether any changes had occurred since primary treatment. In some comments, the men described their prostate specific antigen (PSA) value. "The PSA value today is 1.1." or "After radiotherapy (RT) my PSA-value was 0. Now it is 2.0 and is increasing (more than 0.5) within 4 months." The men also reported local and/or skeletal metastases. One man wrote: "The disease has spread." Some comments were related to the treatments the men had or had not received. Examples include: "I've had 8 sessions of chemotherapy in XX hospital.” and "I am taking Zoladex every 12 weeks.”

The second subcategory contains patients' experiences of their illness, for example, “Tired. Very weak” and "Cannot have sexual intercourse, no erections." One man wrote at the 3-month follow-up, "I have pain in my hips and down my legs," and repeated that comment at the 1-, 2-, 3- and 5-year follow-ups. He wrote in his last comment, "I still have pain in my one hip and leg. It started at the end of RT." The men also explained how they managed problems such as difficulty with urinating: "I always have to organize my days and to urinate, for example, before leaving with the car or before I take a walk; this provides some security and makes life easier to live."

The men also wrote about other matters important to their overall health, including accidents as well as illness. One man wrote, "I got a clot in my left eye. I was an in-patient in a medical ward in XX hospital." They also wrote about having to seek help from a discipline other than the oncology ("I have undergone hip-replacement surgery (with very good results) left hip in autumn 2005”) or receiving other diagnoses ("I have RA," "I have Parkinson's disease," "I got a hernia after treatment," or "I've suffered from systematic atrophy since 1996.")

Some men wrote about their medication-which drugs they were taking and why: "I take nitro-glycerine before every effort. $1 \mathrm{~g}$ Paracetamol for back trouble. Sometimes one pill Dextropropoxifen + Paracetamol," or as another man wrote: "I've been taking a large amount of Glucocorticoid, at present 10 mg a day." Comments associated to this category were more frequently written during the first 8 years of the survey with peaks in year one (T1-T4) and year five (T7) after baseline (Figure 2).

\subsection{Clarifications of Answers to the Survey}

Out of the men's comments, 40\% (304/747) were sorted into this second largest category of comments aimed to allow the researcher to better understand the patients' other answers. Some of the comments mentioned the number of a particular question (“Question 37: erection”, “Question 15: Sometimes when I urinate I have some pain in the beginning”, "Question 56: Lanzo, Zocord”). However, a large proportion of these comments were written in order to enable for the researchers to understand that the responses to the survey had nothing to do with the prostate cancer, but were related to other ailments or diseases. ("Have poor strength in the knee and lower leg. It is these problems and not my prostate problems underlying my response to questions 62 - 70 and 57 - 59", "Had surgery to remove stomach about 10 years ago. Can easily be affected by... large food portions" "Had 2 small strokes during the 3 last years, affecting the legs and my entire body"). Comments in this category were most frequent at baseline (T1) and between the three-month and one-year follow-ups (T3-T4; Figure 2).

\subsection{Descriptions of Well-Being despite the Cancer}

In this category the men $(95 / 747 ; 13 \%)$ took the opportunity to convey their experiences of their life situation. Despite treatments and remaining problems, the comments were generally optimistic in tone. Some wrote of how they had accepted their situation and how their lives were getting back to a "normal” everyday life: "I've learned to live with these problems and it's working out well" and "I'm working part time now as a vocational teacher, so I think things are starting to work out." They wrote about regaining their sense of self and getting back their strength: “As I write this I'm starting to feel like myself again, I'm able to do things again.” They expressed feeling well despite having to live with the side effects of the treatment: "Apart from my sex life I feel 
great." One man wrote about how he and his wife tried to live in the present and support each other: "My life is good even though my wife has Alzheimer's. Her good humour makes life more than bearable. We both live in the present, which is important." Another man wrote about the importance and pleasure of having a supportive family: "I have accepted the situation. I have an understanding family and a wonderful wife who supports me. We have been married for 45 years." Although comments in this category were more and less evenly distributed during the first 8 years from baseline, there was a small peak year five (T7; Figure 2).

\subsection{Experiences of Care and the Need for Contact with Health Care}

Four percent (33/747) of the men's comments were sorted into this category of needs and positive and negative thoughts and feelings about health care. Some of the men wanted to send greetings to staff: "A big hello to everyone at 'the radio shop'!" or "Highest rating for health-care in the county!" There were also varied comments revealing the men's opposite feelings after the treatments. One patient said, "I'm pleased and grateful for the treatment I have received for my PC!" but others revealed dissatisfaction and disappointment: "Why can't I get any help?" and "I also met a doctor who had no understanding at all when I asked for help with my tired legs. I can only hope no one else gets treated that badly."

Some men used the questionnaire to express a need for interaction with the health care professionals and a wish to contact the physician for various reasons. Their expressions mostly revealed a need for more information about further management of PC: "I would like to visit you again" or "What can be done now? An answer from doctor XX would be appreciated!” Comments included in this category were evenly distributed over time with a peak in year two (T5; Figure 2).

\section{Discussion}

In our longitudinal study a total of 897 men with prostate cancer returned 4443 questionnaires. Of these 372 participants (41\%) had responded at least once to the open-ended question, i.e., $17 \%$ of the returned questionnaires. In line with other studies [12] [25], most of the comments were either related to the influence of the cancer on the men's overall health or a clarification of the answers in the survey. The majority of participants wrote between one to four comments during the study period. As in results of other studies focusing on the frequency of responses to an open-ended question over time [25] [26], we too found that the frequency of comments shifted over time. Comments clarifying answers to the survey were most frequent in the first year post-EBRT, while comments related to the prostate cancer's influence on health began to rise three months after ERBT-start and stayed steady in the following years before beginning a decline in year eight (Figure 2). This may indicate that the men have different concerns at different times, possibly because their initial concerns, which focused on survival, might have been resolved by the two-year follow-up. Similar experiences of PC's influence on men's health during this time, and balancing a changed life and uncertainty as the time goes was also reported by others [27].

Our overall interpretation is that the men took the time to write comments mainly to explain to the researchers when their scoring on the survey was related to health problems other than the PC. The analysis also revealed that the men used the open-ended question to communicate experiences of their health, illness, lives, and care. This is similar to the findings in other studies [12] [13] [28]. Maliski and Litwin [25] found that such comments contain clarifications of answers in the survey and provide elaboration and contextualization of participants' symptoms and care. Similarly, in a recently published study of needs for psychological support among patients with head and neck cancer [29], participants expressed the importance of the context of their responses and acknowledged that their responses would be different in other circumstances and context.

As in the study by Corner et al. [12], most of the comments in the present study seemed to illustrate a process of the men's efforts to make meaning of the illness for themselves through conveying their feelings, experiences, facts, explanations, and needs for contact with health care. According to Wallace and Storms [5], identifying the needs of men with PC is an essential step in understanding their experience of this disease. In the study by Powel and Clark [30], 48 of the 71 men surveyed after PC surgery added comments to the open-ended question at the end of the interview. Our result also reveals the respondents' wish to say more than a response scale allows and speaks in favour of including an open-ended item in surveys. According to Foddy [31], some respondents appreciated the opportunity to express themselves in their own words rather than choosing suggested answers. Open-ended questions might allow the participants to write more spontaneously, creatively and person- 
ally than is possible in a forced-choice survey; thereby making it feasible for the researcher to understand the world as seen by the participants, and grasp the strength of their feelings [15] [31] [32].

Using free-text comments, Corner et al. [12] showed that experiencing good support from health care has a great impact on patients' health, their self-management of illness, and the effects of the disease and treatment. Combined with PROM, such comments can enable evaluation and improvement of health care services, particularly if health care professionals are involved [12] [14]. Similarly a study from Denmark based on a patient satisfaction survey showed that free-text comments in questionnaires were more useful than the actual number of satisfied and not satisfied patients, and these comments could be used to improve health-care services by making it more person-centered [14]. In line with others [12] [33] [34] our results, support that open-ended questions could be useful for researchers and health-care providers, to address and identify needs of improvement not only of questionnaires but also treatment regimens and health-care in general. Furthermore, analysis of open-ended questions may provide valuable data about patients' individual needs and expectations related to the health-care services [12] [13] [35]. Our results and others' showed that health care professionals should have a greater focus on patients' needs for support during the whole disease trajectory [36] [37], an effort taken seriously in Sweden by the current development of contact nurses for different cancer trajectories [38]. Others too have described the benefits of placing nurses as "navigators" or "guiding lights" for patients [39] [40]. A role that could possibly be expanded beyond the acute phase, as some of the men's comments indicated they were in need of contact with health care later in the disease trajectory.

Thus, it is likely that by adding a comment the men took the opportunity to reveal something important to them beyond the issues asked for in the questionnaire. If this is in fact the case, it raises the question of whether the researchers sending out the HRQOL questionnaires responded to the men's questions. This in turn moves the issue of including an open-ended item in a forced-choice survey into the ethical realm concerning researchers' appropriate responses to those comments and their obligation to analyze and present the content of these comments to a broader audience [11]. Including such a question is an opportunity for patients to voice their opinion, and ignoring such data in the analysis, according to O'Cathain and Thomas [11], is unethical. Such questions may also help to balance power between researchers and participants and give participants an opportunity to ask about health-care issues, express concerns about the research, and talk about issues that are important to them [11] [12]. Although not necessarily representative, open-ended questions are described as usable since they provide valuable data not revealed by quantitative studies [11] [12] [35] [41]. These questions may provide a valuable supplement to quantitative patient-satisfaction surveys [12] [14], as open-ended questions allow respondents to provide concrete suggestions for improvement of care, something also found by others [14] [33] [34].

This study has strengths and limitations. The longitudinal design and the use of an open-ended question produced results outside the standardized questionnaire that better captured the men's thoughts and feelings about PC and their treatment. Further, such questions allow the participants to express their views and discuss issues of priority to them. However, the results cannot be viewed as representative experiences of all men undergoing the treatment for PC. Using such paper-based questionnaires have acknowledged limitations. Individual writing skills might influence the frequency and content of responses, and we had no opportunity to probe and expand such responses as would be possible in a verbal interview. Web- or phone-based questionnaires might make the answers more understandable as could depth-interviews [32]. Failure analysis comparing the participants with non-participants, with no free-text comments, could not be performed due to missing data regarding education levels and employment among non-participants. This may reduce the possibility to draw conclusions and generalize the results. The final categorisation of responses was generated from patient responses and in consensus between the co-authors.

\section{Conclusions}

Comments on open-ended questions in a PROM-survey often contain additional information about the participants' health and quality of life issues not revealed in the closed-ended questions. It also shows the need for large population surveys that further explore the area because of the limited attention given to these issues. The results of this study show that participants' comments on open-ended questions in a PROM-survey make it possible for the researchers to understand their scoring on the survey, as well as important aspects of their lives during and after PC treatment that are not measured by a scaled questionnaire. The data from free-text comments reinforced the need for greater emphasis by cancer services to support individuals to self-manage follow- 
ing completion of PC-treatment. Our results also complement the ongoing discussion regarding the potential benefit of adding open-ended questions to a standardized closed-ended PROM-questionnaire, especially in a prospective long-term study after treatment of PC.

We recommend that an ethical discussion takes place before adding an open-ended item to a PROM-survey, in order to ensure that proper care is taken of participants' answers and thoughts. By using such questions in a questionnaire, health-care professionals and researchers can increase their understanding of people's reactions to and expectations of health care services and manage this knowledge based on the patients' perspective to improve care to care users. Furthermore, open-ended questions may help capture a broader picture of patients' experiences of HRQL-related issues than closed-ended questions may. If the intent is not to use and understand patients' responses, then open-ended questions should be omitted on a questionnaire.

\section{Acknowledgements}

We wish to express our sincere gratitude to Helena Ekegren Hällgren, RN, Axlagården, Umeå, for her valuable data collection and input during the analysis of the material.

We also wish to acknowledge all the men for their willingness to share their experiences.

\section{Funding}

This investigation was supported by grants from the Lion’s Cancer Research Foundation at Umeå University and the Cancer and Traffic Injury Fund.

\section{References}

[1] Cancerfondsrapporten (2015) http://www.cancerfonden.se

[2] Adolfsson, J. (2003) Health-Related Quality-of-Life Assessments in Patients with Advanced Cancer of the Prostate. PharmacoEconomics, 21, 241-247. http://dx.doi.org/10.2165/00019053-200321040-00002

[3] Fransson, P. (2008) Patient-Reported Lower Urinary Tract Symptoms, Urinary Incontinence, and Quality of Life after External Beam Radiotherapy for Localized Prostate Cancer-15 Years’ Follow-Up. A Comparison with Age-Matched Controls. Acta Oncologica, 47, 852-861. http://dx.doi.org/10.1080/02841860701654325

[4] Jakobsson, L. (2002) Indwelling Catheter Treatment and Health-Related Quality of Life in Men with Prostate Cancer in Comparison with Men with Benign Prostatic Hyperplasia. Scandinavian Journal of Caring Sciences, 16, 264-271. http://dx.doi.org/10.1046/j.1471-6712.2002.00096.x

[5] Wallace, M. and Storms, S. (2007) The Needs of Men with Prostate Cancer: Results of a Focus Group Study. Applied Nursing Research, 20, 181-187. http://dx.doi.org/10.1016/j.apnr.2006.08.008

[6] Fransson, P., Lund, J.A., Damber, J.E., Klepp, O., Wiklund, F., Fosså, S., et al. (2009) Quality of Life in Patients with Locally Advanced Prostate Cancer Given Endocrine Treatment with or without Radiotherapy: 4-Year Follow-Up of SPCG-7/SFUO-3, an Open-Label, Randomised, Phase III Trial. The Lancet Oncology, 10, 370-380. http://dx.doi.org/10.1016/S1470-2045(09)70027-0

[7] Zerbib, M., Zelefsky, M.J., Higano, C.S. and Carroll, P.R. (2008) Conventional Treatments of Localized Prostate Cancer. Urology, 72, S25-S35. http://dx.doi.org/10.1016/j.urology.2008.10.005

[8] Fransson, P., Damber, J.E. and Widmark, A. (2009) Health-Related Quality of Life 10 Years after External Beam Radiotherapy or Watchful Waiting in Patients with Localized Prostate Cancer. Scandinavian Journal of Urology and Nephrology, 43, 119-126. http://dx.doi.org/10.1080/00365590802519396

[9] Katz, A. (2007) Quality of Life for Men with Prostate Cancer. Cancer Nursing, 30, 302-308. http://dx.doi.org/10.1097/01.NCC.0000281726.87490.f2

[10] Kvale, S. (1996) Interwiews: An Introduction to Qualitative Research Interviewing. Sage, Thousand Oaks.

[11] O’Cathain, A. and Thomas, K.J. (2004) “Any Other Comments?” Open Questions on Questionnaires-A Bane or a Bonus to Research? BMC Medical Research Methodology, 4, 25. http://dx.doi.org/10.1186/1471-2288-4-25

[12] Corner, J., Wagland, R., Glaser, A. and Richards, S.M. (2013) Qualitative Analysis of Patients' Feedback from a PROMs Survey of Cancer Patients in England. BMJ Open, 3, e002316. http://dx.doi.org/10.1136/bmjopen-2012-002316

[13] Pill, R., Wood, F.C., Renold, E., Robling, M., Edwards, A., Wilkinson, C., et al. (2003) Welsh Women’s Comments about Breast Problems and the Care Given: A Qualitative Study in the Community. European Journal of Cancer Care, 12, 240-248. http://dx.doi.org/10.1046/j.1365-2354.2003.00407.x 
[14] Riiskjaer, E., Ammentorp, J. and Kofoed, P.-E. (2012) The Value of Open-Ended Questions in Surveys on Patient Experience: Number of Comments and Perceived Usefulness from a Hospital Perspective. International Journal for Quality in Health Care, 24, 509-516. http://dx.doi.org/10.1093/intqhc/mzs039

[15] Polit, D. and Beck, C. (2008) Nursing Research: Generating and Assessing Evidence for Nursing Practise. Lippincott, Williams \& Wilkins, Philadelphia.

[16] Schuwirth, L.W. and van der Vleuten, C.P. (2003) ABC of Learning and Teaching in Medicine: Written Assessment. BMJ, 326, 643-645. http://dx.doi.org/10.1136/bmj.326.7390.643

[17] Trost, J. and Hultåker, O. (2007) Enkätboken (The Book about Surveys). Studentlitteratur, Lund.

[18] Fransson, P. and Widmark, A. (2007) 15-Year Prospective Follow-Up of Patient-Reported Outcomes of Late Bowel Toxicity after External Beam Radiotherapy for Localized Prostate Cancer. A Comparison with Age-Matched Controls. Acta Oncologica, 46, 517-524. http://dx.doi.org/10.1080/02841860601113596

[19] Widmark, A., Fransson, P. and Tavelin, B. (1994) Self-Assessment Questionnaire for Evaluating Urinary and Intestinal Late Side Effects after Pelvic Radiotherapy in Patients with Prostate Cancer Compared with An Age-Matched Control Population. Cancer, 74, 2520-2532. http://dx.doi.org/10.1002/1097-0142(19941101)74:9<2520::AID-CNCR2820740921>3.0.CO;2-Q

[20] Fransson, P., Bergstrom, P., Lofroth, P.-O. and Widmark, A. (2006) Five-Year Prospective Patient Evaluation of

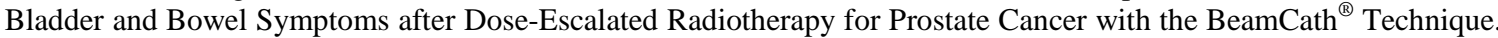
International Journal of Radiation Oncology*Biology*Physics, 66, 430-438. http://dx.doi.org/10.1016/j.ijrobp.2006.05.007

[21] Fransson, P., Tavelin, B. and Widmark, A. (2001) Reliability and Responsiveness of a Prostate Cancer Questionnaire for Radiotherapy-Induced Side Effects. Supportive Care in Cancer, 9, 187-198.

[22] Hsieh, H.-F. and Shannon, S.E. (2005) Three Approaches to Qualitative Content Analysis. Qualitative Health Research, 15, 1277-1288. http://dx.doi.org/10.1177/1049732305276687

[23] Graneheim, U.H. and Lundman, B. (2004) Qualitative Content Analysis in Nursing Research: Concepts, Procedures and Measures to Achieve Trustworthiness. Nurse Education Today, 24, 105-112. http://dx.doi.org/10.1016/j.nedt.2003.10.001

[24] Downe-Wamboldt, B. (1992) Content Analysis: Method, Applications, and Issues. Health Care for Woman International, 13, 313-321. http://dx.doi.org/10.1080/07399339209516006

[25] Maliski, S.L. and Litwin, M.S. (2007) Unsolicited Written Comments: An Untapped Data Source. Oncology Nursing Forum, 34, 142-147. http://dx.doi.org/10.1188/07.ONF.142-147

[26] Rich, J.L., Chojenta, C. and Loxton, D. (2013) Quality, Rigour and Usefulness of Free-Text Comments Collected by a Large Population Based Longitudinal Study-ALSWH. PLoS ONE, 8, e68832. http://dx.doi.org/10.1371/journal.pone.0068832

[27] Jonsson, A., Aus, G. and Bertero, C. (2010) Living with a Prostate Cancer Diagnosis: A Qualitative 2-Year Follow-Up. The Aging Male, 13, 25-31. http://dx.doi.org/10.3109/13685530903424170

[28] Armes, J., Crowe, M., Colbourne, L., Morgan, H., Murrells, T., Oakley, C., et al. (2009) Patients’ Supportive Care Needs beyond the End of Cancer Treatment: A Prospective, Longitudinal Survey. Journal of Clinical Oncology, 27, 6172-6179. http://dx.doi.org/10.1200/JCO.2009.22.5151

[29] Richardson, A.E., Morton, R. and Broadbent, E. (2015) Psychological Support Needs of Patients with Head and neck Cancer and Their Caregivers: A Qualitative Study. Psychology \& Health, 30, 1288-1305. http://dx.doi.org/10.1080/08870446.2015.1045512

[30] Powel, L.L. and Clark, J.A. (2005) The Value of the Marginalia as an Adjunct to Structured Questionnaires: Experiences of Men after Prostate Cancer Surgery. Quality of Life Research, 14, 827-835. http://dx.doi.org/10.1007/s11136-004-0797-8

[31] Foddy, W. (1993) Constructing Questions for Interviews and Questionnaires. Cambridge University Press, Cambridge. http://dx.doi.org/10.1017/CBO9780511518201

[32] Patton, M. (2002) Qualitative Research and Evaluation Methods. SAGE, London.

[33] Kemp, K., Warren, S., Chan, N., McCormack, B., Santana, M. and Quan, H. (2015) Qualitative Complaints and Their Relation to Overall Hospital Rating Using an H-CAHPS-Derived Instrument. BMJ Quality \& Safety, pii: bmjqs-2015004371. http://dx.doi.org/10.1136/bmjqs-2015-004371

[34] McLemore, M.R., Desai, S., Freedman, L., James, E.A. and Taylor, D. (2014) Women Know Best—Findings from a Thematic Analysis of 5,214 Surveys of Abortion Care Experience. Women's Health Issues, 24, 594-599. http://dx.doi.org/10.1016/j.whi.2014.07.001

[35] Phelps, C., Wood, F., Bennett, P., Brain, K. and Gray, J. (2007) Knowledge and Expectations of Women Undergoing 
Cancer Genetic Risk Assessment: A Qualitative Analysis of Free-Text Questionnaire Comments. Journal of Genetic Counseling, 16, 505-514. http://dx.doi.org/10.1007/s10897-007-9086-3

[36] Vaartio-Rajalin, H. and Leino-Kilpi, H. (2011) Nurses as Patient Advocates in Oncology Care: Activities Based on Literature. Clinical Journal of Oncology Nursing, 15, 526-532. http://dx.doi.org/10.1188/11.CJON.526-532

[37] Bergenmar, M., Nylen, U., Lidbrink, E., Bergh, J. and Brandberg, Y. (2006) Improvements in Patient Satisfaction at an Outpatient Clinic for Patients with Breast Cancer. Acta Oncologica, 45, 550-558. http://dx.doi.org/10.1080/02841860500511239

[38] Swedish Government Inquiries (2009) A National Cancer Strategy for the Future-Summary. Reports SGO, SOU 2009:11, Stockholm. http://www.regeringen.se/rattsdokument/statens-offentliga-utredningar/2009/02/sou-200911/

[39] Case, M.A. (2011) Oncology Nurse Navigator. Clinical Journal of Oncology Nursing, 15, 33-40. http://dx.doi.org/10.1188/11.CJON.33-40

[40] Runge Mahler, P. and Rydahl Hansen, S. (2011) Kontaktsygeplejerske Skaber Kontinuitet for Patienter med Lungekraeft. Sygeplejersken, 9, 46-50.

[41] Greenfield, S., Bryan, S., Gill, P., Gutridge, K. and Marshall, T. (2005) Factors Influencing Clinicians’ Decisions to Prescribe Medication to Prevent Coronary Heart Disease. Journal of Clinical Pharmacy and Therapeutics, 30, 77-84. http://dx.doi.org/10.1111/j.1365-2710.2004.00615.x 